\section{CALLE LIMA: EJE CULTURAL PARA EL DESARROLLO. PLAN PILOTO PARA LA RECUPERACIÓN DE LA ZONA MONUMENTAL DE PIURA} SAHARA ALVARADO \& LEOPOLDO VILLACORTA UNIVERSIDAD NACIONAL. DE PIURA, PIURA-PERÚ, 2016.

RESEÑA DE JOSÉ HAYAKAWA CASAS

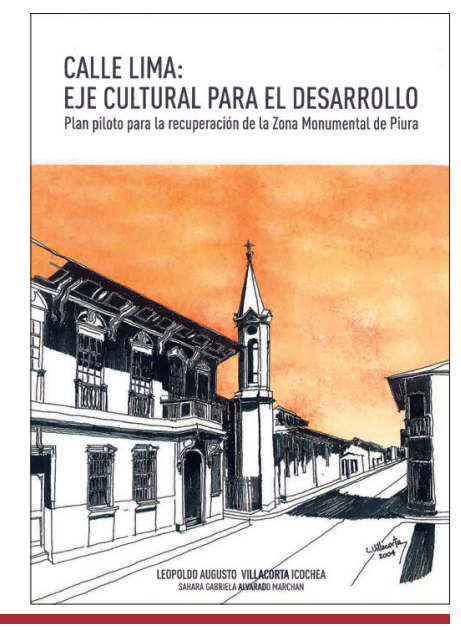

Hablar de este libro invoca referirse al desafío personal asumido por uno de los autores de esta publicación, realizado como una labor permanente, que prueba su enorme compromiso no solo con Piura, ciudad y región donde desarrolla su actividad académica y profesional, sino con las temáticas del patrimonio y sus complejidades en relación a las Zonas Monumentales en el Perú. Evidencia de aquella actitud es que la publicación que aquí se reseña es una segunda edición (la primera fue publicada en 2004). De hecho, la lectura de esta versión es de gran ayuda para evidenciar no solo la tenacidad e involucramiento del Arq. Leopoldo Villacorta, sino también el avance de la depredación y el desinterés respecto de dicha Zona Monumental de Piura.

Esta publicación, escrita a dos manos, contextualiza las posibilidades de actuación a partir de una estructura de contenidos organizada de la siguiente manera: objetivos, antecedentes, situación actual, diagnóstico-posibilidades, recuperación arquitectónica y urbana, y conclusiones. Dicha forma de organizar la información se ve apuntalada por la incorporación de la sección titulada"Anexo: estado situacional actual del Centro Histórico de Piura".

Los objetivos son desarrollados con precisión y se enfocan en la misión de esta obra:

1. Recuperar la calle Lima... mediante un proyecto de Puesta en valor, para convertirla en un eje cultural y turístico del Centro Histórico (Zona Monumental) de la ciudad de Piura... 2. Recuperar y conservar inmuebles coloniales y/o republicanos, declarados Patrimonio Monumental, en 'convi- vencia' con edificaciones contemporáneas; revitalizando el ambiente urbano de la calle Lima, como inicio y ejemplo (Plan piloto)... 3. Promover el uso en las edificaciones de materiales de la zona, como el adobe, el barro y constructiva ancestral (la quincha)... (Alvarado \& Villacorta, 2016, p. 25)

Los "Antecedentes", abordan el contexto histórico general, y abarcan desde la fundación de ciudades, villas y reducciones del siglo XVI hasta el desborde poblacional motivado por la Reforma Agraria en la segunda mitad del siglo XX. En la reconstrucción de este devenir histórico, son explicados ciertos procesos históricos notables, tales como la fundación de la ciudad de Piura, el origen y conformación de la estructura urbana de San Miguel de Piura en el siglo XVIII -citando un valioso texto de 1767 de Mario Cicala acerca de los edificios y techos de las casas de Piura-, en el siglo XIX -citando un valioso texto de 1858 de Antonio Raymondi acerca de las viviendas de Piura-y en el siglo XX -se desarrolla in extenso el terremoto de 1912 y el escenario de la reconstrucción, la declaración de Monumentos, Ambientes Urbano-Monumentales y Zonas Monumentales en Piura-.

La sección "Situación actual: diagnóstico-posibilidades" detalla el perfil actual de la ciudad de Piura y el caso especíico de la Zona Monumental de Piura, e incluye una planimetría general y numerosas fotografías (vistas interiores y exteriores) de edificios y espacios públicos integrantes del Patrimonio Cultural de la Nación peruana que conforman dicha Zona Monumental. la caña; así como también tecnología
En la cuarta parte, "Recuperación arquitectónica y urbana", se desarrolla propiamente la intervención propuesta, definiendo con claridad los criterios y sus componentes, especialmente a partir de la recuperación y revaloración de su tecnología constructiva y espacio ancestral, tales como las cualidades espaciales y constructivas de la vivienda en la costa durante la Colonia y la República. Ello se contrasta con la propuesta de utilización de materiales y sistemas constructivos ancestrales en usos contemporáneos. En esta misma sección se comparte el registro de edificaciones monumentales existentes, elaborado a partir de una ficha de inventario, con el apoyo de los estudiantes de la Facultad de Arquitectura y Urbanismo de la Universidad Nacional de Piura. En este libro se han seleccionado cinco casos de inmuebles emblemáticos, estudiados considerando su denominación, localización, datos legales, cuadro de áreas, tipología, usos, estado de conservación, referencias históricas, registro fotográfico, aspectos arquitectónicos, constructivos y estructurales. Toda esta información va acompañada por información planimétrica del estado actual. Esta sección concluye en la propuesta para el Ambiente Urbano Monumental Calle Lima (tramos calle Huancavelica avenida Sánchez Cerro), que implica el inicio de 13 tipos de actividades de intervención. Asimismo, existe una propuesta para la implementación de la Escuela Taller San Miguel de Piura, que retomaría la positiva experiencia de la Cooperación Española en Hispanoamérica.

Finalmente, son destacables las conclusiones, las cuales ayudan a argumentar el sentido de este esfuerzo de estudio-propuesta en una zona urbana patrimonialmente privilegiada pero en franca degradación-anulación. Un valioso extra lo representa la sección de anexos, donde el Dr. Leopoldo Villacorta desarrolla el "Estado situacional actual del Centro Histórico de Piura", actualizando el registro a noviembre de 2015. Para ello continúa con el registro de la totalidad de sus bienes integrantes del Patrimonio Cultural de la Nación, a partir de una ficha de inventario y con el apoyo de los estudiantes de Arquitectura de la Universidad Nacional de Piura. En el libro se consignan la planimetría general con la delimitación oficial, 88 fichas de inventario monumental y la propuesta de desarrollo de un Plan Maestro para el Centro Histórico de Piura a partir de seis aspectos estratégicos. 
Para poder comprender con mayor detalle la trascendencia de esta publicación, es necesario mencionar el programa de una de las entidades convocantes que fomenta este tipo de acciones, las cuales devienen eventualmente en una breve publicación.

Las autoridades detrás del concurso de ideas Tratamiento de Espacios PúblicosRímac fueron la Municipalidad Distrital del Rímac, la Municipalidad Metropolitana de Lima, el Ministerio de Vivienda, Construcción y Saneamiento, y la Agencia de Española de Cooperación Internacional para el Desarrollo (AECID). Esta última fue creada en 1988 como el único órgano ejecutivo de la política española de cooperación internacional para el desarrollo, y desde 1990 viene ejecutando en el Perú el programa Patrimonio para el Desarrollo, el cual tiene como principal objetivo generar el desarrollo sostenible de las comunidades a partir de la puesta en valor del patrimonio, en tanto participe activo de numerosas intervenciones en distintos centros históricos del país. Destacan entre sus actuaciones la restauración de la Casona de San Marcos en Lima, la Casona Velarde Álvarez en Huamanga, los trabajos en el Valle del Colca, entre otros. Además, la AECID implementa escuelas talleres, con el propósito de instruir mano de obra especializada en el ámbito de la restauración, para así hacer partícipe del proceso de restauración a la población.

En la segunda década de su implementación, la AECID promovió un nuevo tipo de intervención: el organismo ya no solo se involucra en proyectos de restauración, conservación o puesta en valor sino que apuesta por contribuir a gestar ideas innovadoras en torno a la regeneración urbana en espacios públicos patrimoniales. Para ello, trabaja con organismos públicos comprometidos con desarrollar las propuestas ganadoras. En el año 2000 se inició esa etapa con la convocatoria de un concurso internacional de ideas para la Plaza San Francisco de Asís, en Cusco, que recibió un total de 79 propuestas de diversos países.

Siguiendo ese lineamiento, se ejecutó en septiembre de 2010 una nueva convocatoria, esta vez llamada Cinco Ideas para el Centro Histórico de Lima, que recogió 94 propuestas de 20 países. Debido a los buenos resultados obtenidos, se decidió en junio de 2011 invitar a los 15 equipos finalistas a participar

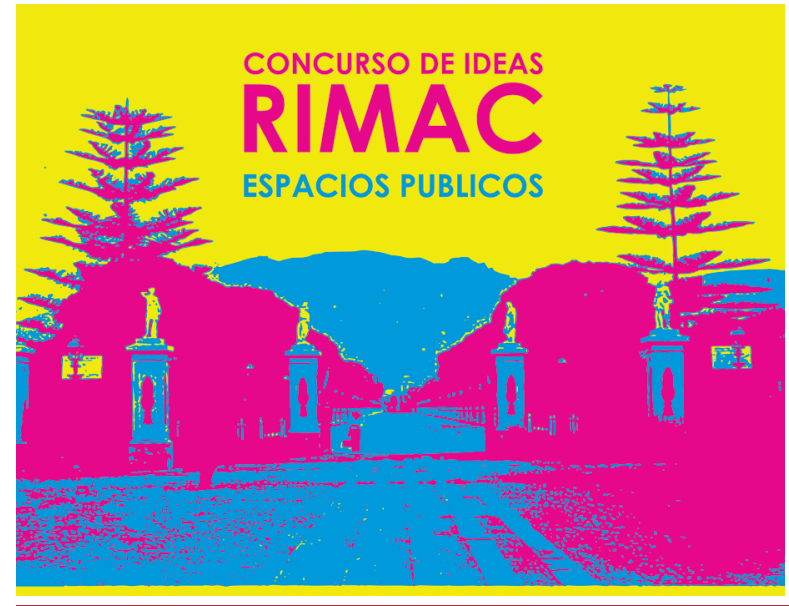

CONCURSO DE IDEAS - RÍMAC: ESPACIOS PÚBLICOS

AGENCIA ESPAÑOLA DE COOPERACIÓN INTERNACIONAL PARA EL DESARROLLO CAECID] PROGRAMA DE COOPERACIÓN HISPANO PERUANO, LIMA-PERÚ 2015.

RESEÑA DE JARIM MELGAR MONTES

del concurso de ideas Tratamiento de Espacios Públicos-Rímac. Este incluía como lugares de trabajo al eje Paseo de Aguas-Alameda de los Descalzos-Alameda de los Bobos; y a la Plazuela de Presa y entorno. Todo culminó, buen hábito de $A E C I D$, con la realización de una pequeña publicación, en la que se explica de manera ágil y sencilla todo el proceso, y se exhiben las propuestas.

El libro se divide en dos partes fundamentalmente. La primera desarrolla tres puntos. Como inicio, se desarrolla una explicación de las bases de participación donde se establecen los espacios públicos a intervenir, los objetivos, el cronograma, los premios, las normas de presentación y las consideraciones. Destaca, entre los premios para las propuestas ganadoras, el establecimiento de un vínculo laboral entre los equipos vencedores y la Municipalidad Distrital del Rímac, con el propósito de llevar el resultado a un nivel de proyecto para su posterior ejecución. El segundo punto que se trata en la primera sección es la difusión del concurso, la exhibición de los resultados en el sitio web oficial del programa en el Perú. Por último, en la tercera sección se exhibe la trasparencia del concurso mediante la conformidad de actas por parte del jurado calificador.

La segunda parte de la publicación está compuesta netamente por todas las propuestas, organizadas según el espacio a intervenir. El aspecto innovador del proyecto ganador para el eje Paseo de Aguas-Alameda de los Descalzos-Alameda de los Bobos radica en la composición de una secuencia espacial a través de una trama peatonal, la cual la haría visible desde el cerro San Cristóbal. Además, en el proyecto se establecen tres etapas de ejecución: en primer lugar, la integración por tratamiento peatonal del paseo y las alamedas; una segunda etapa, en la que se considera fundamental la participación ciudadana, pues la trama ayuda a generar un mobiliario modular que alberga cierta actividad específica y que la población determinaría dónde insertar; y, finalmente, una tercera, que implica la consolidación de los usos que propicie el mobiliario mediante un cambio de zonificación a comercio, lo cual alentaría mayor afluencia para el eje. En el caso de la Plazuela de Presa y entorno, la propuesta vencedora propone un espacio dual que respeta el ingreso para la Quinta de Presa, monumento principal del lugar, y permite tener un espacio barrial que fomente diversas actividades, con una losa deportiva multiusos, tratamiento de losas a desnivel y mobiliario urbano.

Expuesto todo lo anterior, queda invitarlos a revisar esta publicación para empezar a visualizar al espacio público patrimonial como un eje catalizador de actividades, un centro vitalizado que propicie la recuperación de su entorno inmediato, especialmente al ser un espacio público dentro de un centro histórico. Es también recomendable revisar las otras convocatorias, realizadas en Barrios Altos, en cinco plazuelas a lo largo del eje Áncash, así como lo hecho en el centro histórico de Huamanga, cuyo principal protagonista es la Plaza Mayor. 


\section{JORNADAS INTERNACIONALES SOBRE LA FRONTERA HISPANO-PORTUGUESA Y SUS FORTIFICACIONES AYUNTAMIENTO DE BADAJOZ [EDITOR] AYUNTAMIENTO DE BADAJOZ, BADAJOZ-ESPAÑA, 2014.}

RESEÑA DE DIEGO CELIS ESTRADA

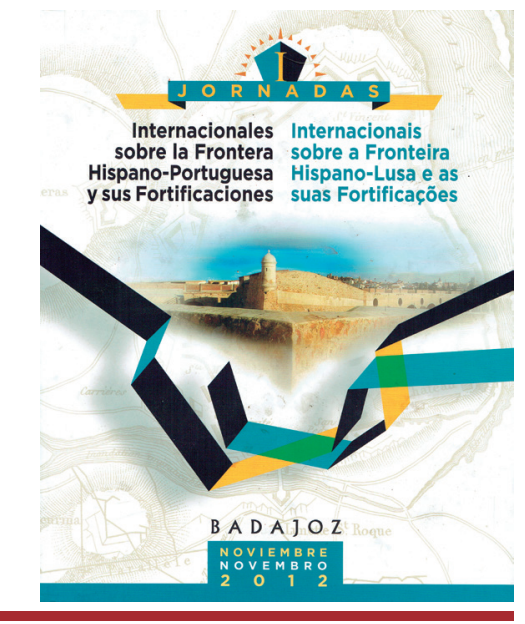

La presente publicación es el resultado de las I Jornadas Internacionales sobre la Frontera Hispano-Portuguesa y sus Fortificaciones, celebradas entre los días 8 y 10 de noviembre de 2012 en Badajoz, organizadas en secciones, que incluyeron a reconocidos especialistas europeos y americanos en diversas materias (Geografía y territorio, Historia, Patrimonio, Arquitectura y Urbanismo), así como de los estudios del territorio limítrofe entre España y Portugal, los cuales contemplan las distintas relaciones socioculturales que allí se suscitan y la respectiva arquitectura militar de frontera. Puede deducirse de lo anterior que dicho conjunto de relaciones expresa un sistema cultural único, ya que se trata de una de las fronteras más antiguas de Europa, fijada parcialmente en 1267 en el Tratado de Badajoz y complementada poco después con el Tratado de Alcañices. Además, se conceptúa a la frontera como un territorio fértil para crear nuevas oportunidades de afirmación patrimonial, en el contexto regional, transfronterizo, nacional e incluso internacional.

Previo al inicio de la investigación del tema, a manera de inauguración de las jornadas, se abordó la misión e importancia del Comité Científico Internacional de ICOMOS sobre la Fortificaciones y Patrimonio Militar (ICOFORT), resaltando las directrices que sigue: la Carta de Venecia (1964), el Documento de Nara sobre la Autenticidad (1994), y otros documentos doctrinales como la Carta de Washington (1987) y la Carta de Itinerarios Culturales (2008). Además, se analizó a manera de ejemplo el caso del Caribe fortificado, específicamente la isla de Puerto Rico.
La estructura de este libro cuenta además con una organización en cinco partes: "Espacio y Territorio", "Historia”, el "Patrimonio", "Urbanismo y Arquitectura" y "Arquitectura Militar de La Raya: un Sistema Único". Como colofón se propone la constitución de una red de fortificaciones hispano-portuguesas y de La Raya, y su reconocimiento por la UNESCO.

En el primer capítulo, se parte del entendimiento del espacio y territorio de la raya ibérica hispano-portuguesa en tanto franja territorial histórica, elástica, un territorio humanizado de estrechas relaciones socioeconómicas, culturales y de bloqueo, de asentamientos militarizados de vida civil compartida. Además, se resalta que las cuencas fluviales y redes camineras son las que conforman los soportes básicos de la organización del territorio trasfronterizo, de la articulación de los asentamientos poblacionales y de las relaciones socioeconómicas, a través de los contados pasillos trasversales que canalizan los flujos circulatorios.

En la segunda sección, que contiene el estudio histórico, se plantea la frontera como un todo indivisible en el que interactúan al unísono una serie de variables económicas, fiscales, sociales, políticas, administrativas, militares y culturales, las cuales contribuyen a moldearla, y a definir la compleja estructura que forma como un conjunto, cuyos caracteres varían en función del tiempo y el espacio. Se enfatiza el proceso por el cual los primeros trazados en el papel se traducirían después en la realidad material de la fortificación de la frontera. Además, estudia la evolución, cambios e importancia que adquirió a lo largo de la historia.
En el tercer capítulo se aborda el valor patrimonial de dicho territorio fronterizo definiendo, entendiendo y determinando qué es patrimonio, qué se entiende por arquitectura defensiva, y qué bienes y cuántos componen la arquitectura defensiva española. También se da a conocer la importancia de los Planes Nacionales de Patrimonio Histórico Español, los cuales resultan de la trasferencia de competencias sobre patrimonio a las Comunidades Autónomas, y tienen como propósito establecer una metodología de actuación para la conservación y restauración que permita favorecer la correcta coordinación de actuación a los diversos organismos implicados en la protección, conservación, investigación y difusión del patrimonio fortificado en España. Finalmente, se resalta los criterios de intervención que se deben tener en cuenta para poder plantear proyectos de conservación, restauración y rehabilitación.

En la cuarta sección se estudia la arquitectura defensiva en la frontera desde su concepción paisajística, asociada a casos de planificación y proyecto. Para ello, se analiza los modelos de gestión y planificación urbanística y patrimonial, así como su incidencia sobre las actuaciones en el patrimonio defensivo; se revisa la incidencia que diversas cartas y recomendaciones tienen en este ámbito; y se identifican las tendencias y buenas prácticas sobre la arquitectura defensiva fronteriza, siempre en el marco del proceso de planificación y gestión de las intervenciones.

El quinto y último capítulo resalta el valor del patrimonio histórico-militar de la frontera hispano-portuguesa, lo cual facilita su comprensión total en el espacio y el tiempo para su óptima gestión en tanto un específico territorio cultural, así como en cuanto a su conservación y su difusión.

Finalmente, si bien el presente estudio se focaliza en la importancia, y la gestión cultural y patrimonial del caso de la raya ibérica hispano-portuguesa, puede observarse que las variables que en él se presentan son comunes a todas las fronteras actuales y pasadas, por ejemplo, el Limes romano. Por lo tanto, esta publicación puede ser tomada como referencia para entender las fronteras no como un borde, sino como un territorio que cuenta con una importancia económica, cultural y patrimonial. 
Como su nombre lo indica, El Urbanismo Inka del Cusco. Nuevas Aportaciones brinda un recuento de las investigaciones realizadas, y sintetiza los últimos aportes sobre las construcciones y la conformación física del Cusco inka. La dirección científica y edición estuvo a cargo de cuatro profesionales: los arquitectos Crayla Alfaro, José Beltrán-Caballero y Ricardo Mar, y el arqueólogo Ramiro Matos.

Sin desmerecer otros trabajos reconstructivos como los llevados a cabo por el Museo de la Nación (Lima), Kubler, Chávez Ballón, Paredes, Bauer, Farrington y el propio Agurto, este es sin duda el más completo e integral intento de aproximación a la reconstrucción física de la ciudad inka del Cusco.

Cabe mencionar que la columna base del libro tiene como antecedente los trabajos reconstructivos que los arquitectos José Beltrán-Caballero (colombiano) y Ricardo Mar (español) llevaron a cabo sobre Sacsayhuamán y los recursos hídricos que posee el territorio cusqueño, así como la tesis doctoral de Beltrán-Caballero sobre la forma urbana del Cusco, cuyo director justamente fue Mar, y se realizó con el apoyo del arqueólogo Ramiro Matos (otro de los editores del libro), el Instituto Smithsoniano y la Universidad de Tarragona. El trabajo de los arquitectos tuvo como colofón un modelo 3D interactivo del Cusco inka. En el presente libro se constata el aporte de ambos arquitectos en el número de páginas en las que participan ambos como autores colaboradores.

La presentación de esta publicación da buena cuenta de la positiva visión con que el Gobierno de la ciudad ha asumido su liderazgo y está aportando a la construcción de valiosas estrategias de gestión del centro histórico del Cusco. La perspectiva institucional que la gerente del centro histórico de la Municipalidad del Cusco, la Arq. Crayla Alfaro, comparte en este breve texto, ayuda a comprender -y valorar- no solo la apuesta por contribuir al buen vivir en una ciudad histórica como Cusco, sino a la comprensión de la especificidad urbana de su centro histórico: la apuesta conmemorativa municipal de creación del Centro de Documentación de la Gerencia de la Ciudad Histórica -siguiendo referentes como La Habana Vieja-, la formulación del Plan Maestro del Centro Histórico como instrumento de gestión de enfoque estratégico y gerencial, y la definición y prio-

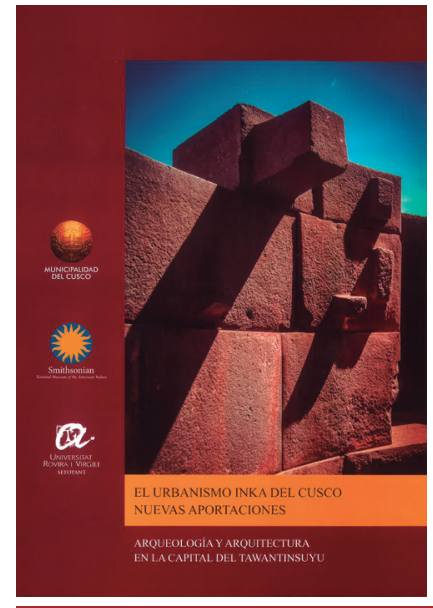

EL URBANISMO INKA DEL CUSCO. NUEVAS APORTACIONES CRAYLA ALFARO, JOSÉ BELTRÁN-CABALLERO, RICARDO MAR Y RAMIRO MATOS [EDICIÓN CIENTÍFICA] MUNICIPALIDAD DEL CUSCO - NATIONAL MUSEUM OF AMERICAN INDIAN - UNIVERSITAT ROVIRA I VIRGILI, CUSCO-PERÚ, 2014.

RESEÑA DE CARLOS ENRIQUE GUZMÁN

rización de cuatro líneas de acción y sus correspondientes estrategias para contribuir al logro de tan nobles fines.

Este libro se desarrolla en seis capítulos. En el primero se hace un recuento de la superposición de construcciones urbanas que se han ido sucediendo sobre las de factura inka, desde el Virreinato hasta la actualidad, y se plantea la posibilidad de hacer una reconstrucción lo más fidedigna posible del Cusco primigenio.

En el segundo capítulo se exploran los restos visibles de terrazas, estructuras y huacas que rodeaban el núcleo central de la llamada "ciudad Puma", recurriendo a fotos aéreas antiguas y vestigios actuales. Se incluye al inicio un notable plano de síntesis, donde sobre una foto aérea se delinean los restos inkas de edificios, terrazas, caminos y huacas, mientras que en el siguiente capítulo se presentan los caminos de este entorno.

El cuarto es el más voluminoso de los capítulos. Cierra magistralmente el tema de la reconstrucción física del Cusco inkaico, y recoge toda la información sobre muros, edificaciones, rocas sagradas y andenes presentes en el mismo casco urbano. A partir de dicha información, una vez sintetizada en plano, se propone una reconstrucción hipotética del casco inka, la cual se completa con la reconstrucción 3D del templo solar del Hanan Cusco, construido sobre el apu Sacsayhuamán, donde destacan las murallas escalonadas en zigzag y las tres torres mencionadas en las crónicas.

Los dos últimos capítulos (quinto y sexto) complementan lo presentado en los precedentes. Recurren a las narraciones de los cronistas respecto a las fiestas celebradas en el Cusco, pero se enfocan en analizar el uso del espacio y los posibles límites de la capital inka. Además, es un lujo contar en estas secciones con la participación de dos especialistas renombrados, Ariadna Baulenas (colaboradora científica del Seminario de Topografía Antigua de la Universitat Rovira i Virgili y asesora del Museu de les Cultures del Món de Barcelona) y Donato Amado (Ministerio de Cultura, Región Cusco).

Lo particular de esta publicación es la notoria intención de mostrar imágenes y fotos de los restos, así como reconstrucciones hipotéticas del Cusco inka, quizá porque del total de autores de los capítulos, tres son arquitectos que trabajan interdependientemente con diversos especialistas.

Ello obliga a reflexionar respecto de una consideración que debe estar presente en este tipo de trabajos: la participación multidisciplinaria. No obstante, este esfuerzo va más allá de dicha consideración, y se instala en la dinámica del trabajo colaborativo interinstitucional, ya que tanto la Municipalidad del Cusco, como el National Museum of American Indian y la Universitat Rovira i Virgili han cooperado intensamente, en la medida de sus posibilidades, para materializar un aporte académico maduro e innovador. Sin duda, son dos singulares fortalezas que invitan a sumergirse en sus interesantes páginas... 